\title{
The Design and Development of Enhanced Thermal Desorption Products
}

\author{
R. Humble, H. Millward, A. Mumby, R. Price
}

\begin{abstract}
This research study is based on a knowledge-transfer collaboration between The National Centre for Product Design and Development Research (PDR) and Markes International Ltd. The aim of the two-year collaboration has been to implement design tools and techniques for the development of enhanced thermal desorption products. Thermal desorption is a highly-specialised technique for the analysis of trace-level volatile organic compounds. This technique allows minute quantities of these compounds to be measured; however, there is an increasing demand from customers for greater sensitivity over a wider range of applications, which means new design methodologies need to be evaluated. The thermal desorption process combines a number of disparate chemical, thermal and mechanical disciplines, and the major design constraints arise from the need to cycle the sample through extremes in temperature. Following the implementation of a comprehensive product design specification, detailed design solutions have been developed using the latest $3 D$ CAD techniques. The impact of the advanced design techniques is assessed in terms of improved product performance and reduced development times, and the wider implications of new product development within small companies are highlighted.
\end{abstract}

Keywords: thermal desorption, product design, SME.

\section{Introduction}

Thermal desorption is a highly-specialised technique for the capture, concentration and analysis of trace-level volatile organic compounds (VOCs) in real world samples. A typical application is the measurement of airborne VOC pollutants in an industrial setting, such as a chemical processing plant [1]. The thermal desorption technique, in conjunction with gas chromatography and mass spectrometry, allows minute quantities of these substances to be detected and measured [2]. However, the demand from customers for greater sensitivity over a wider range of applications is increasing. The recent security concerns over chemical and biological weapons within the UK and USA provides a vivid example of the need for an accurate and sensitive technique to monitor air quality. A collaborative research programme was establishe in this area to identify optimal product design and development techniques for the novel thermal desorption process. The thermal desorption process combines analytical chemistry, materials science, transient heat transfer, mechanical drive systems and electronic control. Thermal desorption products are traditionally labbased capital equipment, and the disparate areas of expertise have meant that product development has tended to be treated as somewhat of a 'black art'. The development of these products has been driven by the application of analytical science, whereby thermal desorption is now a proven, reliable concept, but it has been reliant on 'traditional' design and manufacturing techniques. New market opportunities, such as portable instruments and embedded on-line products, have highlighted the need to investigate a wider range of product design and development techniques in order to progress the technology.

This paper reports the application of new design and development tools within a small company specialising in thermal desorption equipment. The context of this study is important because new product development activities within small and medium-sized enterprises provide higher financial returns than practically any other type of similar investment [3]. SMEs are often in a prime position to identify innovative new products as a consequence of their close working relationships with customers and suppliers; however, the majority of the product development literature focuses on design tools and activities within large well-established companies. The literature on design and development within SMEs is more limited in scope [4]. This is surprising given the fact that SMEs play a key role in most European economies. It has been estimated, for example, that $95 \%$ of the three million businesses in the UK employ fewer than 20 people [5]. Thus their performance as product developers is a matter of no small concern. SMEs typically operate in a resource constrained environment, and there can be a tendency for small companies to conduct product development in an ad hoc manner [6]. In order for SMEs to maintain their competitive advantage in an increasingly harsh international market, they need to adopt best practice design and development techniques.

Advanced design tools, such as computer-aided design (CAD) software, represent an important route for improving competitiveness through enhanced quality and productivity. Integrated CAD-based systems have made a major impact across a range of industries. CAD speeds up design and engineering activities by rapidly capturing design intent and reducing the errors between development stages [7]. A number of researchers have highlighted the benefits of integrating CAD systems within the overall product development process $[8,9]$; however it has also been noted that CAD systems can inhibit innovation if implemented inappropriately and used ineffectively [10]. Therefore the methods by which design and development techniques are implemented are an important consideration. This paper will assess the impact of a CADbased structured design process, which has been applied to the novel design challenges of thermal desorption products. The specific requirements of thermal desorption are presented through a product design specification, and the core component of the thermal desorption instruments is highlighted for re-design and prototype development. The resulting design improvements are assessed through an experimental test programme. The overall impact of the design 
and development techniques is reported in terms of development times and project costs, and the wider implications for new product development within small companies are discussed.

\section{Case-study methodology}

Markes International Ltd was established in 1997 and now operates with a staff of approximately 20 . They specialise in the design and development of thermal desorption capital equipment, and all the key development activities are conducted in-house. This encompasses early concept design, experimental testing and final assembly. The company has successfully developed a range of state-of-the-art laboratory-based products, and their core products are based on the 'Unity' and 'Ultra' thermal desorption instruments, an example of which is shown in Fig. 1. A typical selling price for this type of unit is approximately $\mathcal{E} 20 \mathrm{k}$. The company's client base includes the process industry, key regulatory agencies and the service laboratory sector, with applications ranging from environmental health to materials testing. The company has established an international reputation as a leading supplier of quality thermal desorption equipment, accounting for a $12 \%$ market share across the world and $60 \%$ of the market within the UK.

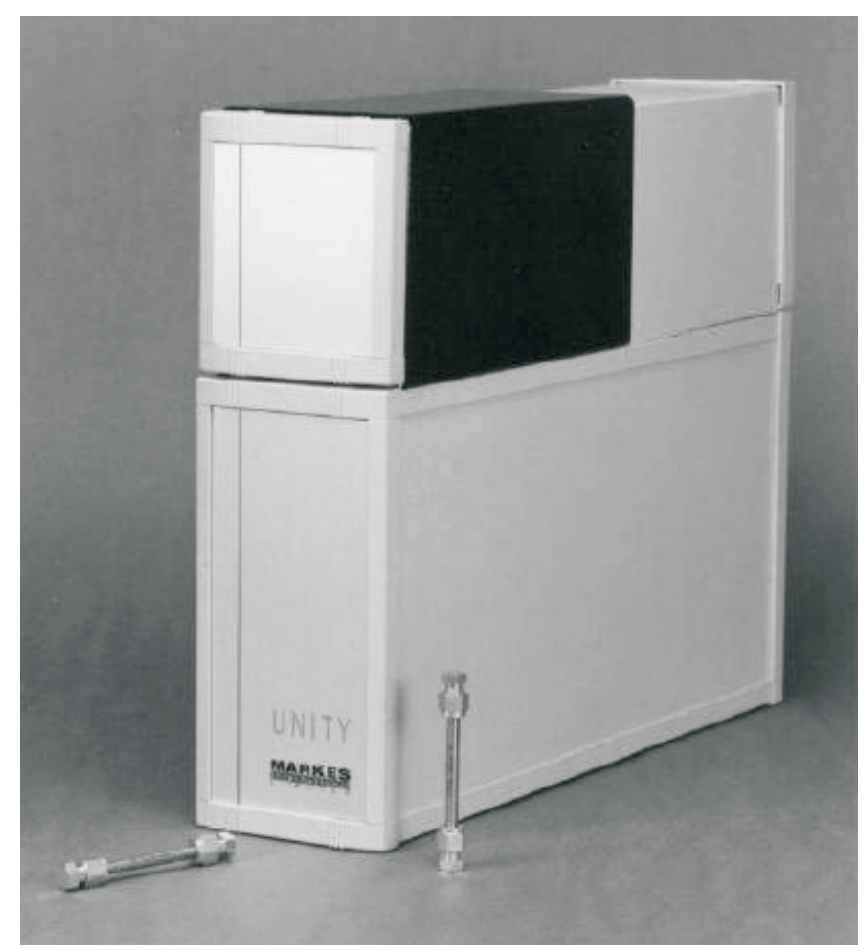

Fig. 1: Example of a 'Unity' thermal desorption laboratory-based instrument

As a result of emerging markets (e.g. building materials emissions and contamination in food and beverages), Markes International has identified new products that will drive significant business growth. In order to bring these new products to market, Markes International formed a partnership with PDR, and this identified the need to introduce a 3D CAD-based design capability to add value through enhanced product performance in combination with a more effective development process. A collaborative KTP (Knowledge Transfer Partnership) programme was established in March 2003, and this paper reports the preliminary results during the first 12 months of the programme.

PDR have employed the KTP model as an effective mechanism for partnership and collaboration with a wide range of SMEs, predominantly in Wales. The KTP strategy has been in operation for over 20 years, and is a government-backed knowledge transfer scheme. The aim of the scheme is to strengthen the competitiveness and wealth creation of the UK by stimulating innovation in industry through structured collaborations with universities and research organisations. KTP is run for the government by Technology Transfer and Innovation Limited (tti). A typical KTP programme is a two-year partnership between one company, one university and tti. Each individual KTP programme is designed to address the key elements central to the successful development of the specific company. The two-year project provides employment for a wellqualified graduate KTP Associate for the duration of the programme. It should be noted that KTP was formerly known as TCS (Teaching Company Scheme) prior to 2003.

All the PDR-based KTP programmes are, or have been, focused on product design, and the numbers reflect the UK trend in that the majority have been based in SMEs. PDR have successfully completed 12 KTP programmes since 1995, seven of which have been with small companies. A typical PDR-based KTP programme implements a new design capability within a 'traditional' manufacturing company. In line with other researchers [11], PDR have found that the KTP model is an ideal vehicle through which to analyse the design-to-manufacturing interface and the associated elements that impact upon new product development within SMEs.

The well-defined management and structure of the KTP process promote a detailed analysis of the company from the university partner's perspective. A close working relationship is developed with the company in the early stages during the drafting of the KTP grant proposal. This is written by the university in collaboration with the company, describing the company and the financial benefits, and quantifying the aims and objectives of the programme. A key feature of the proposal is a detailed 104-week Gantt chart, which defines a programme of work to address the strategic needs of the company. Following the approval process, a grant is awarded and PDR employs an Associate to work full time at the company for two years to meet the project objectives. The Associate is assigned at least one PDR-based supervisor and at least one supervisor from the company. The regular contact with the company fosters a level of trust and co-operation that generates an indepth understanding of the subtle issues and problems inherent in any small company.

KTP programmes are characterised by a commitment to disciplined effective project management through mandatory monthly and quarterly meetings. The monthly meetings between the supervisors and the Associate not only focus on the technical issues within the programme, but also address training and personal development requirements. The quarterly meetings are designated Local Management Committee (LMC) meetings, and are underpinned by support from a tti consultant. LMCs act as the programme's steering group to ensure that the longer-term objectives for the company and Associate are met. The documentation (technical reports, 
executive summaries and presentation material) arising from the structured KTP meetings, in parallel with the weekly informal contact with the company personnel, results in a comprehensive portfolio of case study material, and this provides the foundation to this research study.

\section{Product design specification}

The generic sampling and analysis process for the lab-based thermal desorption instruments can be summarised as follows:

a) The VOCs are 'captured' in sample tubes that contain an absorbent matrix. The sample tubes are located at key points in the area to be analysed (two sample tubes are shown in Fig. 1).

b) The sample tubes (typical volume 100-200 ml) are sealed and transported to the lab-based equipment.

c) The sample tubes are fed into the thermal desorption equipment and an inert gas stream (usually Helium) extracts the VOCs from the sample tubes.

d) The gas stream refocuses the VOCs into the cold trap module, which is electronically cooled and contains an absorbent with a strong affinity for the VOC. e) The cold trap is then rapidly heated, which desorbs the VOCs and concentrates the sample into a smaller volume (typically 100-200 $\mu \mathrm{l}$ ).

f) The concentrated sample is then introduced into a gas chromatograph or mass spectrometer for analysis.

It can been seen that the cold trap module acts as the concentration engine at the heart of all the thermal desorption instruments. The cold trap technology has been developed for the Unity range, and this provides the basis for further design improvements that can be incorporated into replacement products and new products for emerging markets.

The first stage of the re-design process was establishing a product design specification (PDS). The PDS is a central element within the various design documentation, and needs to be reviewed and updated in response to other design output (e.g. test reports and risk analysis). The implementation and maintenance of an appropriate PDS for assemblies and critical components is the first step toward a systematic design process, although this is not always acknowledged by small companies [12]. The cold trap module PDS can be used as an exemplar, and key sections are highlighted in Table 1 in order to define the main design challenges.

Table 1: Key sections of the PDS for the cold trap module

\begin{tabular}{|c|c|}
\hline Performance & $\begin{array}{l}\text { - Constant cold trap cooling to give a minimum temperature of }-15^{\circ} \mathrm{C} \text {. } \\
\text { - Intermittent 'firing' to heat the trap and achieve desorption at a maximum temperature of } 300^{\circ} \mathrm{C} \text {. } \\
\text { - Materials compatible with temperature extremes and absorbent matrices. } \\
\text { - Electrical supply to power both the 'cooling' and 'heating' elements. } \\
\text { - Product will run for ten years, and service stock will be required for a further five years. } \\
\text { - Product will be usable for up to } 24 \text { hours per day, operating a seven-day week. } \\
\text { - Product must avoid ice formation. }\end{array}$ \\
\hline Interfaces & $\begin{array}{l}\text { - Upstream connection and input from sample tube. } \\
\text { - Downstream connection to Heated Valve (constant operating temperature of } 200{ }^{\circ} \mathrm{C} \text { ), and output to } \\
\text { analyser. } \\
\text { - The critical connection between the Cold Trap Module and the Heated Valve must avoid condensa- } \\
\text { tion, and there should be no interconnecting tubing. } \\
\text { - The cold trap module will need to operate as a key sub-assembly within a range of new products. }\end{array}$ \\
\hline Environment & $\begin{array}{l}\text { - Upstream ambient conditions assumed to be } 30{ }^{\circ} \mathrm{C} \text {. } \\
\text { - Relative humidity in the range } 5 \%-95 \% \text { (non-condensing). } \\
\text { - Module must withstand transit-vibrations and shock loading up to an acceleration of } 10 \times 9.8 \mathrm{~ms}^{-2} \text {. } \\
\text { - Noise levels must adhere to laboratory regulations. }\end{array}$ \\
\hline Quality & $\begin{array}{l}\text { - No failure should cause any hazard for any operator. } \\
\text { - The functional failure rate should be greater than } 1 \text { in } 50 \text { - based on primary testing. } \\
\text { - Product must comply with all relevant EC legislation and BS regulations. }\end{array}$ \\
\hline
\end{tabular}




\begin{tabular}{|l|l|}
\hline $\begin{array}{l}\text { Materials } \\
\text { Manufacture }\end{array}$ & $\begin{array}{l}\text { - Materials and manufacturing techniques must conform to in-house assembly and approved sub-con- } \\
\text { tracted manufacturing processes. } \\
\text { - Products will be built individually to order, with approximately } 40 \text { cold trap modules assembled per } \\
\text { year. } \\
\text { - Manufacturing techniques must be appropriate for low-volume, batch fabrication. } \\
\text { - The competitive driver is the delivery of required performance at a reduced cost. }\end{array}$ \\
\hline Maintenance & $\begin{array}{l}\text { - The cold trap module must be maintenance free. } \\
\text { - Product must be designed to minimise the servicing requirements. } \\
\text { - Absorbent traps must be changeable without the risk of breaking the traps. }\end{array}$ \\
\hline
\end{tabular}

\section{Advanced design techniques}

The selection and implementation of a 3D CAD system was a key aspect of the first year of the KTP collaboration. Prior to this partnership, the company were reliant on a basic 2D CAD package that was used predominantly for final manufacturing drawings. With the focus on new product challenges and inherently complex assemblies, there was a clear need to make the transition to a solids- and surface-modelling package. Early 3D systems required costly UNIX-based hardware, but with the advent of cost-effective, mid-range packages, full 3D CAD functionality has become a viable option for SMEs.

During the early stages of the KTP programme, the company's current and future design requirements were reviewed and documented. A number of mid-range CAD packages were short-listed and tested against the company's requirements. The system selected was the AutoDesk Inventor CAD package. Once the first phase of training had been completed, the 3D CAD software was employed on all new projects, and the old 2D system was kept running in the background for comparison. The preliminary indications are that $3 \mathrm{D}$ solid modelling is a more efficient and productive approach to the design of thermal desorption products. The main benefits of the new 3D CAD system can be summarised as follows:

- The ability to clearly communicate the design intent of new product concept is a central feature within 3D CAD systems. Different drawing views can be created instantly from a solid model, and this removes the ambiguity associated with 2D drawings. This allows non-technical personnel to provide meaningful feedback much earlier in the design cycle. Furthermore, at the end of the development process the 3D CAD images significantly enhance brochures and scientific presentations.

- Thermal desorption products are essentially large, complex assemblies comprising hundreds of mechanical parts and precise interfaces; the 3D environment efficiently manages these assemblies. Furthermore, the 3D CAD can assess fit and tolerance problems early in the design process.

- Design lead-times have reduced by approximately $15 \%$ because it is much simpler to make quick design changes, and error-checking time has reduced. This, in turn, has reduced the number of engineering change notes. Changes to a $3 \mathrm{D}$ model automatically propagate through to all relevant drawings, and this is further enhanced through bi-directional associativity and parametric design.

The immediate impact of the 3D CAD has been to speed up the design and development cycle; however the new design software provides the foundation for strategic changes in the way thermal desorption products are designed and developed. The $3 \mathrm{D}$ design data can integrate with downstream systems to facilitate analysis and verification, and expand manufacturing options. Analysis techniques, notably finite element analysis, have been applied to a wide range of industries. The main design challenges within thermal desorption products are driven by the extremes in temperature, therefore thermal analysis software to model the transient heat transfer between critical components would link well with the 3D solid models. This form of thermal analysis should provide a route for evaluating and optimising cold trap performance prior to full experiments and verification testing within the laboratory. It has been highlighted that low-volume manufacturing techniques are needed for the specialised thermal desorption market, therefore zero-tooling rapid manufacture directly from the 3D CAD data may be commercially viable - particularly for bespoke products. The design team have already started to consider stereolithography parts direct from CAD, and this could be extended to sintered metal parts for functional components.

\section{Prototype development}

The development process established a new design concept for the cold trap module, based on the criteria set out in the PDS. Taking into consideration factors such as materials selection and design for manufacture, a detailed design evolved, and the CAD model is shown in Fig. 2. The key temperature-dependent functionality is driven by the absorption/cooling and the desorption/heating components. The absorbent matrices are contained within the central quartz cold trap tube, and this is surrounded by a ceramic cylindrical channel. Continuous cooling is provided by two Peltier coolers located beneath this cylindrical trap. The trap box is positioned on top of a heat sink that helps to regulate heat conduction away from the trap channel. The desorption/heating stage is driven by a metallic-strip heater located on the inner circumference of the ceramic channel. Both the Peltier coolers and the trap heater are powered through the electrical supply.

The operation and performance of the new cold trap module can be characterised by a temperature traverse 


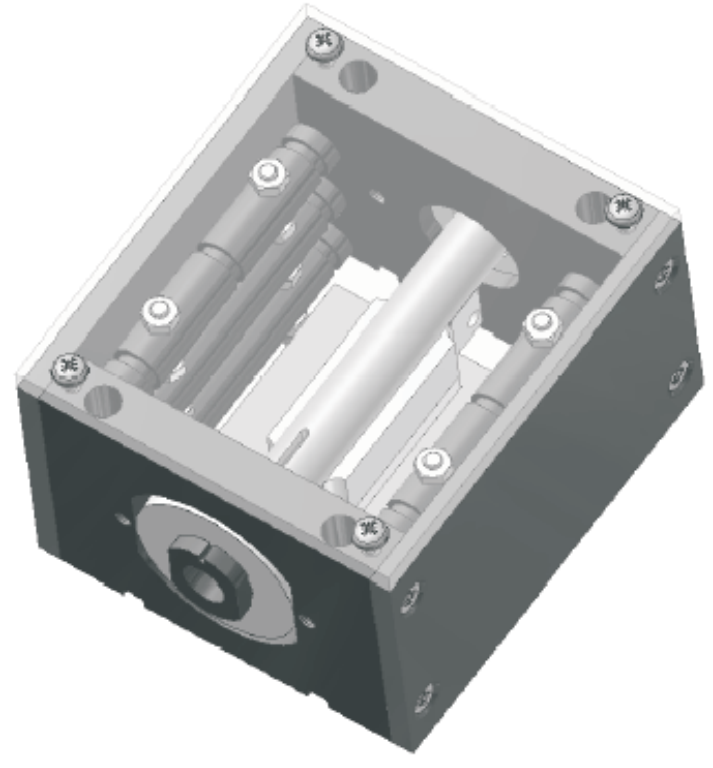

Fig. 2: CAD model of the cold trap module

through the quartz trap during the key cooling and heating phases. This experimental testing is part of the rigorous in-house design verification process, and the data was generated by positioning a thermocouple at known axial positions within the quartz trap. Fig. 3 shows the performance of the default condition, namely continuous cooling, whereby the Peltier coolers are always on and air recirculates through the trap box. It should be noted that the upstream junction of the ceramic trap $(x=10 \mathrm{~mm})$ is at ambient temperature, and the downstream section connects directly to the heated valve assembly $(x=120 \mathrm{~mm})$, which is maintained at a constant temperature of $200{ }^{\circ} \mathrm{C}$. The critical absorbent matrices are located from $x=40 \mathrm{~mm}$ to $x=80 \mathrm{~mm}$, and it can be seen that most of this section is maintained at sub-zero temperatures, close to the specified value of minus $15^{\circ} \mathrm{C}$. The design challenge for this phase of thermal desorption is to generate a distinct step change in temperature at the upstream and downstream interfaces, and thereby create abrupt thermal junctions. The gradual 'S curve' temperature profile evident in Fig. 3 is not ideal, and derives from the thermal communication between adjacent components.

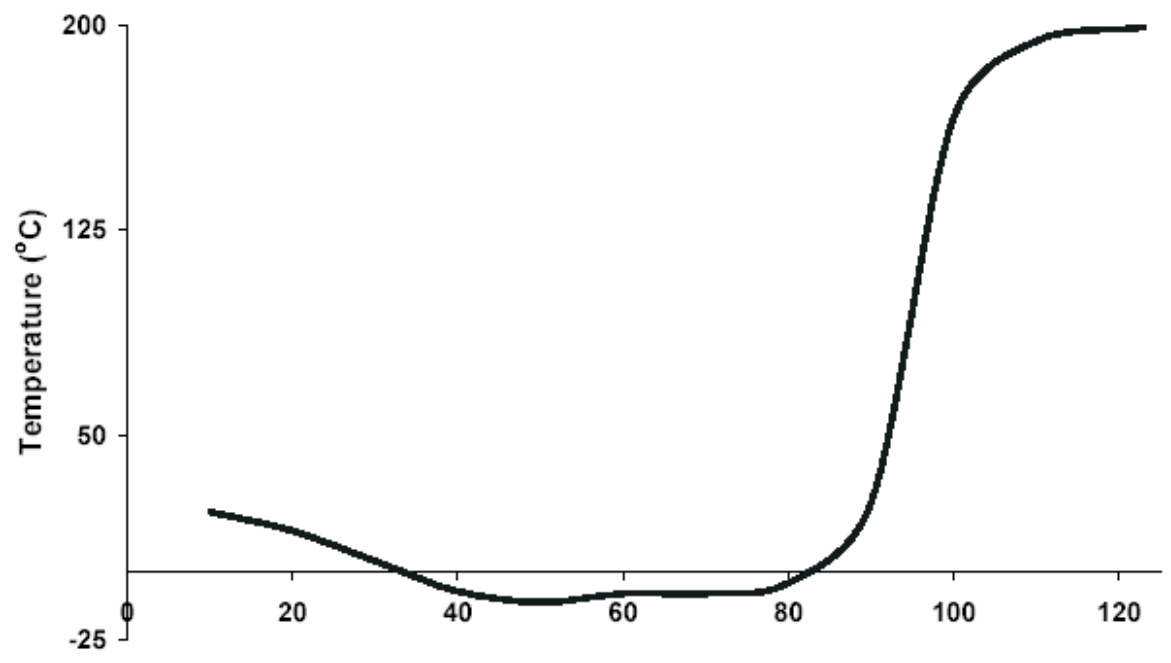

Axial Position $\mathrm{x}(\mathrm{mm})$

Fig. 3: Absorption/cooling temperature profile within the cold trap module
During the desorption phase, the trap heater is 'fired' for approximately five minutes, and the temperature profile for this operation is shown in Fig. 4. The objective for this phase is to maintain the core temperature above $200{ }^{\circ} \mathrm{C}$ from the matrices $(x=40 \mathrm{~mm}$ to $x=80 \mathrm{~mm}$ ) through to the heated valve $(x=120 \mathrm{~mm})$. It can been seen that the peak temperature of $300{ }^{\circ} \mathrm{C}$ occurs within the quartz trap $(x=70 \mathrm{~mm})$, but the temperature drops just below $200{ }^{\circ} \mathrm{C}$ in the zone ahead of the heated valve. The reason for this is that the close proximity of the heated valve to the cold trap module creates conflicting design constraints. The step change in temperature indicated for the absorption phase acts against the need for uniform temperature during the desorption phase. The Peltier coolers remain on when the trap is 'fired', and this generates a cold pocket between the trap and the heated valve. However, the Peltier coolers must remain on in order to produce the abrupt temperature change when the absorption/cooling phase re-commences. One option would be to increase the peak temperature of the trap heaters, but this is an inefficient use of power and may increase the price of the overall unit. These preliminary results provide a sound basis for further development. It is anticipated that innovative solutions will lie in the design of the cold trap module in terms of refined materials properties and configuring precise thermal communication between the key interfaces.

\section{Conclusions \& future work}

The implementation of structured design documentation and advanced design tools has been shown to add significant benefits to the design and development of a specific thermal desorption product. The first phase of a two-year knowledge-transfer collaboration has defined the design challenges through a detailed PDS, and has developed functional prototypes by employing a 3D CAD system. The preliminary results indicate that design-cycle lead times have reduced as a consequence of the new design tools, and product performance is in line with the requirements of the specification, which provides the basis for further design improvements. These findings support the view that, if properly implemented, design tools and techniques can have a significant operational impact within SMEs. 


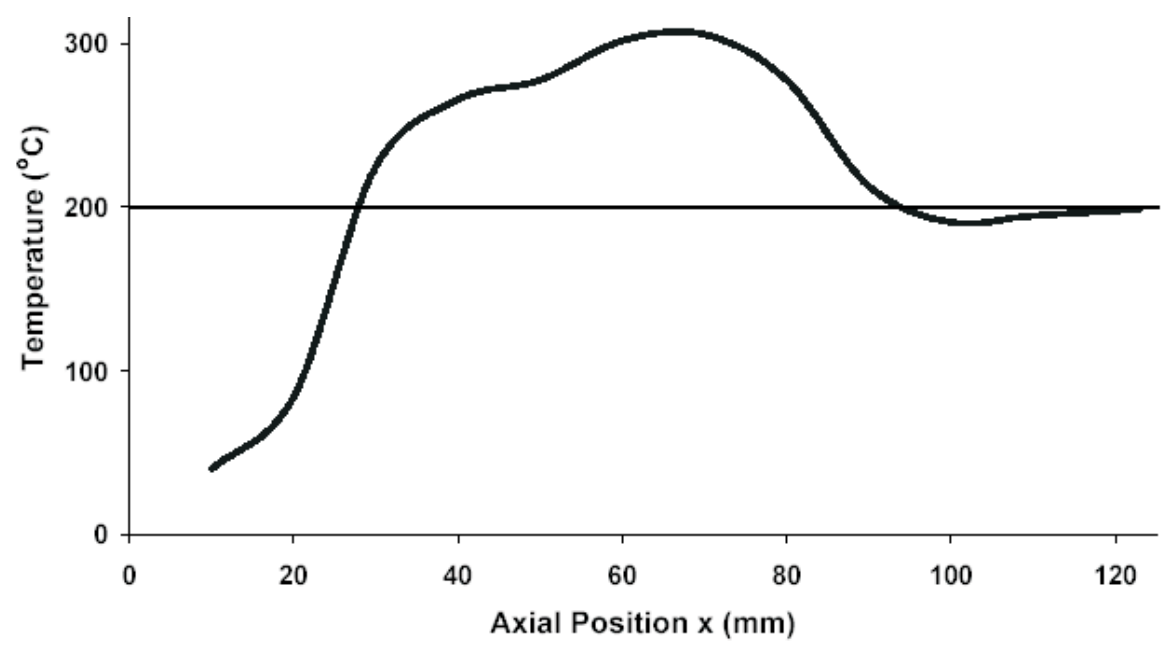

Fig. 4: Desorption/heating temperature profile within the cold trap module

Future work in this area will expand on the research questions highlighted in this study, and evaluate techniques for optimising the thermal desorption products. The thermal characteristics and constraints within the cold trap module have now been defined; therefore, the next phase of research will employ specific analysis tools to refine the thermal desorption process. For example, the 3D CAD data could link directly to thermal analysis software in order to model the transient heat transfer at precise locations within the cold trap module. In order to verify any theoretical design results, a thermal imaging system could also be employed to support the experimental test programme. CAD-based design optimisation should provide a mechanism for reducing project costs, as well as lead times, and thereby deliver tangible commercial benefits directly linked to the new product development process.

\section{References}

[1] Woolfenden, E., Broadway, G.: "An Overview of Sampling Strategies for Organic Pollutants in Ambient Air." Liquid and Gas Chromatography International, Vol. 5 (1986), p. 166-171.

[2] Zha, Q., Oppenheimer, J., Weisel, C.: “The Automated Analysis of Ambient Air Samples by a Thermal Desorption-GC/MS System." Proceedings of the $38^{\text {th }}$ ASMS Conference on Mass Spectrometry and Allied Topics, Tucson, Arizona, 1990, p. 617-625.

[3] Berliner, C., Brimson, J.: Cost Management for Today's Advanced Manufacturing: The CAM-I Conceptual Design. Boston: Harvard Business School Press, 1988.

[4] Brown, R., Lewis, A., Mumby, A.: Enhancing Design Effectiveness in Very Small Companies. Cardiff (UK): Design Engineering Research Centre, 1996.

[5] Daly, M., McCann, A.: "How Many Small Firms?" Employment Gazette, Vol. 100 (1990), p. 14-19.

[6] Millward, H., Lewis, A.: "Product Development Limitations within SMEs: The Drive to Manufacture in the Absence of an Understanding of Design." Proceeding of the $10^{\text {th }}$ International Product Development Management Conference, Brussels, Belgium, 2003, p. 713-723.
[7] Robertson, D., Allen, T.: "CAD Systems Use and Engineering Performance." IEEE Transactions on Engineering Management, Vol. 40 (1993), p. 274-282.

[8] Droge, C., Jayaram, J., Vickery, S.: "The Ability to Minimise the Timing of New Product Development and Introduction." Journal of Product Innovation Management, Vol. 17 (2000), p. 24-40.

[9] Sanchez, A., Perez M.: "Cooperation and the Ability to Minimise the Time and Cost of New Product Development within the Spanish Automotive Supplier Industry." Journal of Product Innovation Management, Vol. 20 (2003), p. 57-69.

[10] Kessler, E., Chakrabarti, A.: "Speeding up the Pace of New Product Development." Journal of Product Innovation Management, Vol. 16 (1999), p. 231-247.

[11] Lipscomb, M., McEwan, A.: The TCS Model: An Effective Method of Technology Transfer at Kingston University. UK: Industry and Higher Education, December, 2001, p. 393-401.

[12] Lewis, A., Walters, A.: "Implications of Inadequate Specification Procedures on New Product Development in Small to Medium-Sized Enterprises." Proceedings of the $9^{\text {th }}$ International Product Development Management Conference, Sophia Antipolis, France, 2002, p. 541-550.

\section{Robert Humble}

Dr. Huw Millward, Ph.D.

e-mail: hmillward-pdr@uwic.ac.uk

Alan Mumby

The National Centre for Product Design \& Development Research (PDR)

University of Wales Institute Cardiff (UWIC)

Cardiff CF5 2YB

Wales, UK

\section{Ryan Price}

Markes International Limited, Llantrisant Business Park Pontyclun CF72 8YW

Wales, UK 